\title{
PREPARATION AND DATING OF MORTAR SAMPLES-MORTAR DATING INTER-COMPARISON STUDY (MODIS)
}

Irka Hajdas $^{1 *} \cdot$ Alf Lindroos $^{2} \cdot$ Jan Heinemeier $^{3} \cdot$ Åsa Ringbom $^{4} \cdot$ Fabio Marzaioli $^{5}$ • Filippo Terrasi ${ }^{5} \cdot$ Isabella Passariello $^{5} \cdot$ Manuela Capano $^{5} \cdot$ Gilberto Artioli $^{6} \bullet$ Anna Addis $^{6} \bullet$ Michele Secco ${ }^{6}$ Danuta Michalska ${ }^{7}$ Justyna Czernik ${ }^{8} \cdot$ Tomasz Goslar $^{8,9} \bullet$ Roald Hayen ${ }^{10} \bullet$ Mark Van Strydonck $^{10} \bullet$ Laurent Fontaine $^{10} \bullet$ Mathieu Boudin $^{10} \bullet$ Francesco Maspero $^{11} \cdot$ Laura Panzeri $^{12} \cdot$ Anna Galli $^{13} \cdot$ Petra Urbanová $^{14} \cdot$ Pierre Guibert $^{14}$

${ }^{1}$ Laboratory of Ion Beam Physics, ETHZ, Otto-Stern-Weg 5, 8093 Zurich, Switzerland.

${ }^{2}$ Dept. of Geology and Mineralogy, Åbo Akademi University, Finland.

${ }^{3}$ Aarhus AMS Centre, Department of Physics and Astronomy, Aarhus University, Denmark.

${ }^{4}$ Department of Art History, Åbo Akademi University, Finland.

${ }^{5}$ CIRCE-INNOVA and Department of Mathematics and Physics, Università della Campania "Luigi Vanvitelli” Italy.

${ }^{6}$ Dipartimento di Geoscienze, Università di Padova, Italy.

${ }^{7}$ Institute of Geology, Adam Mickiewicz University, ul. Bogumiła Krygowskiego 12, 61-680 Poznań, Poland.

${ }^{8}$ Poznań Radiocarbon Laboratory, Poznań Park of Science and Technology ul. Rubież 46, 61-612 Poznań, Poland.

${ }^{9}$ Faculty of Physics, Adam Mickiewicz University, ul. Umultowska 85, 61-614 Poznań, Poland.

${ }^{10}$ Royal Institute for Cultural Heritage, Jubelpark 1, 1000 Brussels, Belgium.

${ }^{11}$ CUDAM, Università di Milano-Bicocca, piazza della Scienza 4, 20126 Milano, Italy.

${ }^{12}$ Dipartimento di Scienza dei Materiali, Università di Milano-Bicocca, via R. Cozzi 55, 20125 Milano, Italy.

${ }^{13}$ CNR-IFN, Piazza L. Da Vinci 32, 20133 Milano, Italy.

${ }^{14}$ IRAMAT-CRP2A, UMR5060 CNRS - Univ. Bordeaux Montaigne, France.

\begin{abstract}
Seven radiocarbon laboratories: Åbo/Aarhus, CIRCE, CIRCe, ETHZ, Poznań, RICH, and Milano-Bicocca performed separation of carbonaceous fractions suitable for ${ }^{14} \mathrm{C}$ dating of four mortar samples selected for the MOrtar Dating Inter-comparison Study (MODIS). In addition, optically stimulated luminescence (OSL) analyses were completed by Milano-Bicocca and IRAMAT-CRP2A Bordeaux. Each laboratory performed separation according to laboratory protocol. Results of this first intercomparison show that even though consistent ${ }^{14} \mathrm{C}$ ages were obtained by different laboratories, two mortars yielded ages different than expected from the archaeological context.
\end{abstract}

KEYWORDS: ${ }^{14} \mathrm{C}$, intercomparison, MODIS, mortar, OSL.

\section{INTRODUCTION}

The idea of performing this intercomparison is rooted in the decades of research conducted by several groups in the field of chronological studies. The very first attempts to date mortars were made soon after the method was established (for example Delibrias and Labeyrie 1964; Stuiver and Smith 1965; Folk and Valastro 1976). However, it was only a few decades later that Van Strydonck et al. (1983a,b), Ringbom and Remmer (1995), and Heinemeier et al. (1997) proposed a more systematic approach to radiocarbon $\left({ }^{14} \mathrm{C}\right)$ dating of mortars. Following this, different methodological developments were undertaken: first by Nawrocka et al. (2005) with cryo-breaking of mortars prior to dissolution and later by Lindroos et al. $(2007,2011)$ with sequential dissolution of mortars. Thanks to the Mortar Dating Project (www.mortardating. com) the ${ }^{14} \mathrm{C}$ dating of mortar became more popular with other laboratories, and new or modified protocols of mortar preparation have appeared (Nawrocka et al. 2009; Marzaioli et al. 2011; Hajdas et al. 2012; Hodgins et al. 2011; Marzaioli et al. 2013; Michalska et al. 2013).

Separation of the carbonate fraction that would only contain carbon fixed in mortar at the time of binding (i.e. the binder) is the main goal of the procedure. This can be achieved by physical means such as sieving (dry or wet) or suspension (density separation) and chemical selection of

\footnotetext{
*Corresponding author. Email: hajdas@phys.ethz.ch.
} 
more reactive anthropogenic fraction. A combination of these two methods has been realized differently by the seven ${ }^{14} \mathrm{C}$ laboratories participating in the intercomparison. However, different procedures distinguish the laboratory protocols; for example by the type of acids applied (i.e. hydrochloric versus orthophosphoric) to produce $\mathrm{CO}_{2}$ fractions for the separation principles (i.e. mostly physical versus mostly chemical) and data analyses $\left({ }^{14} \mathrm{C}\right.$ age profiles versus single fraction ages).

Recently, another approach to dating mortar by optically stimulated luminescence (OSL) has been established. After the first tests on archaeological mortars performed by standard multigrain techniques (Zacharias et al. 2002; Goedicke 2003, 2011; Panzeri 2013), advanced developments by "single grain OSL" technique (SG-OSL), consisting in measurements of luminescence signal of each grain individually, have been carried out (Urbanová et al. 2015, 2016; Urbanová and Guibert 2017a). The methodology consists of systematically combining single grain OSL analyses followed by rigorous statistical data treatment with characterization of microdosimetric properties by SEM-EDX carthography and beta autoradiography (see Urbanová and Guibert 2017a for details and other references). Such dating procedure results in larger uncertainties (5-10\%) but allows to overcome the problems of heterogeneous bleaching. This approach has recently been successfully integrated in several archaeological studies providing chronological classification of building phases for Early Medieval monuments such as Saint Seurin basilica in Bordeaux (Urbanová and Guibert 2017b).

The main goal of the intercomparison was to compare results obtained on the same material. Ideally, such samples should be of known age and consist of homogenous material. As discussed below only two samples fulfilled these conditions. Nevertheless, our study allows us to draw some conclusions and provides insights into future developments of the methods.

\section{SAMPLES}

Four mortar samples were selected for MODIS project included Medieval, Roman and prehistoric lime burial: The first sample, a wall's bedding mortar from the church of Nagu in the Åboland archipelago (Finland) (Sample 1), was available as fine fraction $45-72 \mu \mathrm{m}$ and original pieces. A lime conglomerate from a burial of Cova S'Estora (Son Pellisser) on the island of Mallorca (Spain) (Sample 2), which was described by Van Strydonck et al. (2017), was provided as $<500 \mu \mathrm{m}$ fraction and original pieces of lime. The remains of a medieval mortar mixer from Basel Cathedral Hill (Switzerland) (Sample 3) and a rendering from a Roman wall excavated in the city of Tongeren (Belgium) (Sample 4) were available as original pieces. Figure 1 a-e shows pictures of the MODIS samples documented at ETH laboratory. Hayen et al. (2017, 2016), describe details of petrographic investigations of samples and their archeological context.

\section{METHODS}

In the following preparations methods used by each laboratory (ABO, CIRCE, CIRCe, ETHZ, POZN, RICH, MIL, and IRAMAT-CRP2A Bordeaux) are introduced.

\section{Preparation of Mortar Åbo/Aarhus Team (ABO, Finland/Denmark)}

The principles of the procedure are described in detail in Lindroos et al. (2007), Heinemeier et al. (2010), and Lichtenberger et al. (2015). Wet sieving was applied to the most fine-grained material after crushing the samples with pliers. The $46-75 \mu \mathrm{m}$ fraction is usually selected for the 

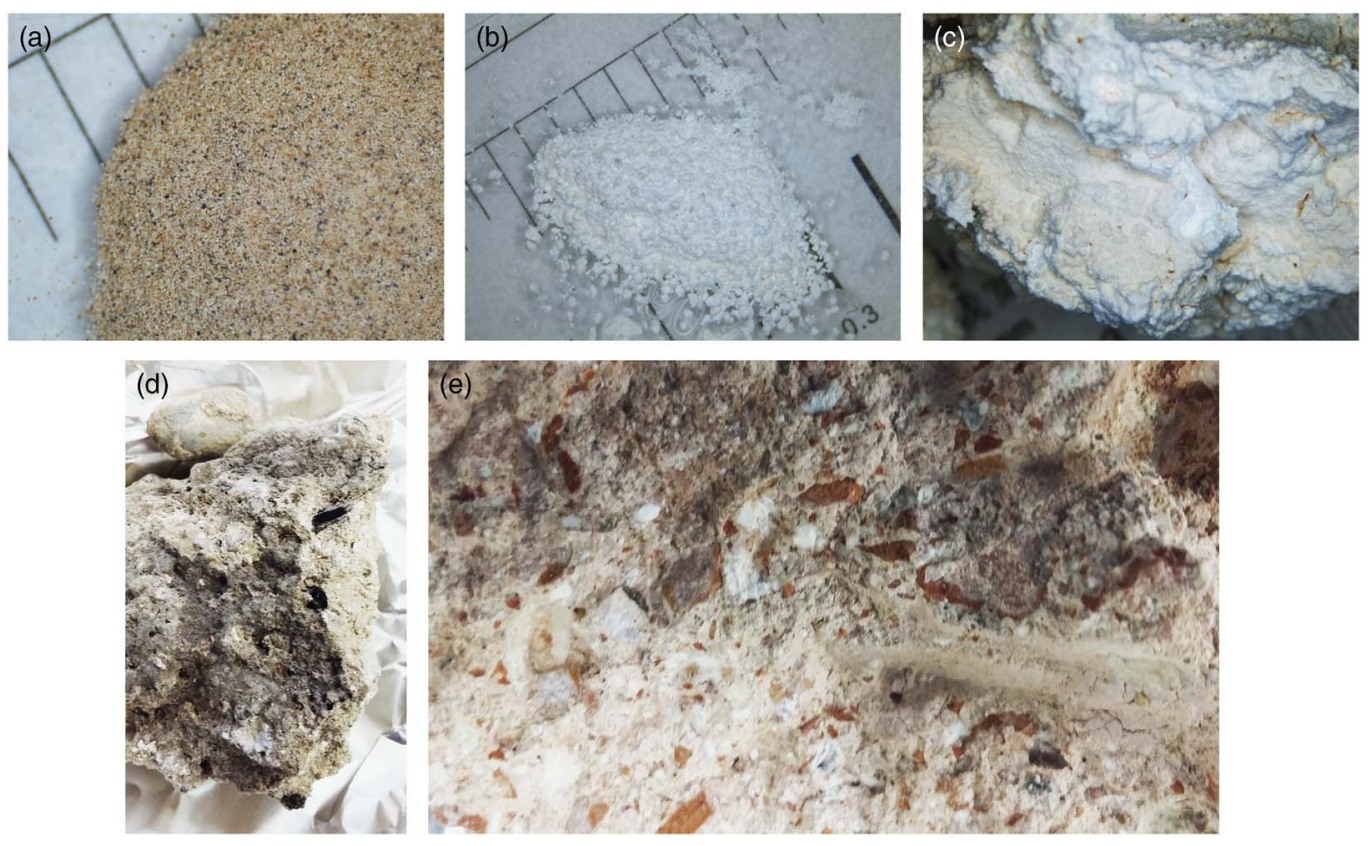

Figure 1 Pictures of MODIS samples distributed among the laboratories: (a) Sample 1-Finnish mortar; (b) Sample 2-Mallorca lime burial $\mathrm{f}<500 \mu \mathrm{m}$; (c) Sample 2-Mallorca lime burial original (F); (d) Sample 3-Basel mortar; (e) Sample 4-Roman cocciopesto.

hydrolysis. Cathodoluminescence (CL) might be used to cross check for purity (presence of natural carbonates) showing presence of unburnt limestone (Lindroos et al. 2007). Coarser grain size fractions (e.g. 300-500 $\mu \mathrm{m}$ ) were checked for alkalinity with phenolphthalein dissolved in alcohol. The hydrolysis was performed with an excess of orthophosphoric acid $\left(\mathrm{H}_{3} \mathrm{PO}_{4}\right)$. In this step about $3 \mathrm{~mL}$ of $85 \%$ acid (water solution) was added from a burette onto the dry sample under vacuum. A typical sample size is around $100 \mathrm{mg}$ of sample powder, but small, crushed lime lumps weighing down to $10 \mathrm{mg}$ have been successfully prepared with the same set up. Several $\mathrm{CO}_{2}$ fractions can be isolated from each sample and usually the first three are collected and dated. To minimize the amount of $\mathrm{CO}_{2}$ from slowly dissolving natural carbonates the first fraction was typically collected as rapidly as possible i.e., after the first $3-10 \mathrm{~s}$ and the second one in the following 20-30 s. The third fraction is usually collected in 60-90 s. The amount of $\mathrm{CO}_{2}$ in each fraction corresponds to $0.2-1.1 \mathrm{mg}$ carbon. Fractions containing $>0.6 \mathrm{mg}$ carbon were split into two vials, one for ${ }^{14} \mathrm{C}$ and the other for stable carbon and oxygen isotope measurements. The vials containing the $\mathrm{CO}_{2}$ gas were submitted to the accelerator mass spectrometry (AMS) ${ }^{14} \mathrm{C}$ Dating Centre at Aarhus University for graphitization and AMS ${ }^{14} \mathrm{C}$ measurements (Vogel et al. 1984). $\delta^{13} \mathrm{C}$ and $\delta^{18} \mathrm{O}$ values were measured using a GV Instruments Isoprime stable isotope mass spectrometer in dual inlet mode to a precision of $0.15 \%$. The final ${ }^{14} \mathrm{C}$ age of the mortar is defined (a) by the plateau of ages of the first fractions (at least two consecutive) or (b) if the first fractions of three different samples from the same building unit agree between each other.

\section{Preparation of Mortar at CIRCE/Università della Campania “Luigi Vanvitelli” (Italy)}

The initial CryoSoniC procedure (Marzaioli et al. 2011), which was developed at CIRCE (Centre for Isotopic Research on Cultural and Environmental heritage), was modified after 
Marzaioli et al. (2013) to Cryo2SoniC in order to increase efficiency of dead carbon suppression. This revised method includes the following steps:

1. Wet (in deionized water) sieving at $500 \mu \mathrm{m}$, which is following up to 3 cycles of wet freezing and thawing aimed to break mortars (i.e. cryo-breaking).

2. The homogenous powder produced undergoes a first ultra-sonication of the homogenous powder for $10 \mathrm{~min}$ with complete water removal to produce a fraction labeled SAND;

3. The residual powder undergoes an extra $30 \mathrm{~min}$ ultra-sonication with not-complete suspension removal (labeled the SUSP fraction).

The centrifuged (at centrifuge acceleration of 7874 times the gravity acceleration for $5 \mathrm{~min}$ ) fractions (SAND and SUSP) are dried $\left(80^{\circ} \mathrm{C}\right.$ overnight) and digested under vacuum with $85 \%$ $\mathrm{H}_{3} \mathrm{PO}_{4}$ to completely evolve $\mathrm{CO}_{2}$ (McCrea 1950). Collected $\mathrm{CO}_{2}$ is graphitized (Marzaioli et al. 2008) and measured by the AMS CIRCE System (Terrasi et al. 2008). The ${ }^{14} \mathrm{C}$ ages for both SAND and SUSP fractions are analyzed with the SUSP fraction considered most suitable (Marzaioli et al. 2013; Nonni et al. 2013).

\section{Preparation of Mortar at CIRCe Università di Padova (Italy)}

As described by Addis et al. (2016), the mortar samples underwent manual cleaning and gentle disaggregation followed by two ultrasonic baths in ultra-pure water for $60 \mathrm{~min}$, each time sampling the suspended fraction. Then, the suspended fraction was centrifuged three times at $6000 \mathrm{rpm}$ for $30 \mathrm{~min}$, each time the solution was replaced with ultra-pure water. In the next step, the fraction was dispersed inside a graduated cylinder with $500 \mathrm{~mL}$ of ultra-pure water for $20 \mathrm{hr}$ in order to obtain dimensional separation of the particles according to Stokes' Law. At the end of the sedimentation time, the uppermost emulsion containing particles with a size less than $2 \mu \mathrm{m}$ was pipetted and filtered by using a vacuum pump system and $0.1 \mu \mathrm{m}$ filters.

Before the ${ }^{14} \mathrm{C}$ dating, the dried fraction was analyzed by isotope ratio mass spectrometry, coupled with X-ray powder diffraction and cathodoluminescence spectroscopy. The ${ }^{14} \mathrm{C}$ analyses were performed at CIRCE/Università della Campania "Luigi Vanvitelli".

\section{Preparation of Mortar at ETH Zurich (Switzerland)}

A modification of method described by Hajdas et al. (2012) involved testing additional grain size fractions. The original method was based on ages of $<32 \mu \mathrm{m}$. However, following the discussion at the workshop dedicated to MODIS ${ }^{1}$, modification has been introduced after Sample 4 was already prepared using only a finest $<32 \mu \mathrm{m}$ fraction. In addition to this, a fraction of 32-63 $\mu \mathrm{m}$ was separated by dry sieving. In case of samples 2 and 3 only fraction of 45-63 $\mu \mathrm{m}$ was targeted, which is similar to what Åbo and Poznań laboratories use. Sample 1 was already pre-sieved to $46-75 \mu \mathrm{m}$ therefore, there was no sieving applied. The separated fine fractions were then dissolved in $85 \% \mathrm{H}_{3} \mathrm{PO}_{4}$. Four time intervals were chosen for collecting $\mathrm{CO}_{2}$ : 0-3 s, 4-6 s, 7-9 s, 10-12 s. Fractions were collected by sequential freezing of $\mathrm{CO}_{2}$, which was evolving in a continuously running reaction, into four separate vials. Typically, the amount of carbon of the first and second fractions are lower than $200 \mu \mathrm{g}$, therefore samples are frozen into the 4-mm-diameter tubes for direct AMS analyses on $\mathrm{CO}_{2}$.

\footnotetext{
${ }^{1}$ Age of anthropogenic carbonates: radiocarbon dating of mortars, limes and stucco. International Workshop on Mortar Dating, Zurich, 9-11 September 2015.
} 
The collected $\mathrm{CO}_{2}(50-100 \mu \mathrm{g}$ C) is analyzed using gas ion source interface for AMS analysis (Fahrni et al. 2010). In an ideal case, the ${ }^{14} \mathrm{C}$ ages of four fractions are expected to form a plateau of ages. However, this is rarely the case and for most of the samples the final age is based on the youngest ${ }^{14} \mathrm{C}$ age or if an agreement (within $2 \sigma$ ) between fractions is achieved, these are used to calculate mean value for the mortar age. In the case of Sample 4, two fractions $(<32$ and $45-63 \mu \mathrm{m})$ were analyzed and showed an agreement within the measurement uncertainty, in effect the results were used to build the mean value, which gives the age of the mortar sample (see Table $\mathrm{S} 1$ in supplementary information).

\section{Preparation of Mortar at Poznań Institute of Geology and Poznań Radiocarbon Laboratory (Poland)}

The preparation protocol of mortar at Poznań laboratory described in Michalska et al. (2017 this volume; Nawrocka-Michalska et al. 2007) has been developed based on experience of different scientific groups (Folk and Valastro 1979; Van Strydonck et al. 1986; Heinemeier et al. 1997; Lindroos et al. 2007; Goslar et al. 2009; Nawrocka et al. 2009; Marzaioli et al. 2013; Nonni et al. 2013; Ringbom et al. 2014; Hayen et al. 2016).

Samples were prepared only after the detailed characterization i.e., petrography, a scanning electron microscope observation (SEM) and chemical analyses using electron dispersive spectrometer (EDS) (Hayen et al. 2016; Michalska et al. 2017 this volume) were completed. These analyses provided information about the mortars components and allowed to design the sample specific preparation steps namely number of fractions needed to be collected for ${ }^{14} \mathrm{C}$ analysis.

In the next step samples 1 and 2 were gently crushed into smaller pieces and dry sieved into grain fractions $(40-63 \mu \mathrm{m}, 63-71 \mu \mathrm{m}, 63-80 \mu \mathrm{m}, 71-80 \mu \mathrm{m}, 80-100 \mu \mathrm{m})$. Samples 3 and 4 were prepared by both methods: dry sieved to obtain appropriate grain fraction and by application of cryobreaking procedure i.e., repeated freezing and thawing of sample to disintegrate its structure and to separate components (Michalska et al. 2017, this volume). Additionally, samples from suspension were also sieved. Sieving was followed by dissolution in $90-95 \% \mathrm{H}_{3} \mathrm{PO}_{4}$ in $80^{\circ} \mathrm{C}$.

In order to choose an appropriate grain fraction and time interval for the gas collection during hydrolysis, tests of the leaching reaction in orthophosphoric acid were performed (Figure 2; for more details see Michalska et al. 2017 in this volume). Depending on the mortar components, the reaction kinetics influence the percentage of carbonates originating from the binder in a first gas portion (Nawrocka et al. 2009a; Michalska and Czernik 2015). The course and rate of leaching reactions reflect the mortars' components.

Petrographic composition of the first two samples MDIC1 and MDC2, i.e., Finnish and Mallorca samples, indicated that two dissolution fractions are sufficient for ${ }^{14} \mathrm{C}$ analysis. This included a fraction from the shortest time of the gas collection during leaching reaction, which is known to provide the most reliable material for dating, and gas collected during a longer dissolution time interval, using the last as a control sample.

Samples such as the cocciopesto MDIC 4 and the mortar mixer MDIC 3 (Hayen et al. 2016; Michalska et al. 2017 this volume), were considered to be difficult materials for dating, due to the presence of ceramic dust or different pozzolanic components (Binda and Baronio 1988; Ringbom et al. 2011). These two samples were prepared as suspension and grain fractions. The dissolution time was minimized and $\mathrm{CO}_{2}$ was collected for dating in very short time intervals (first 1-2 s of leaching reactions). To see the influence of mortar components on the dating results, also a gas portion collected in longer time interval was dated (14 s). 


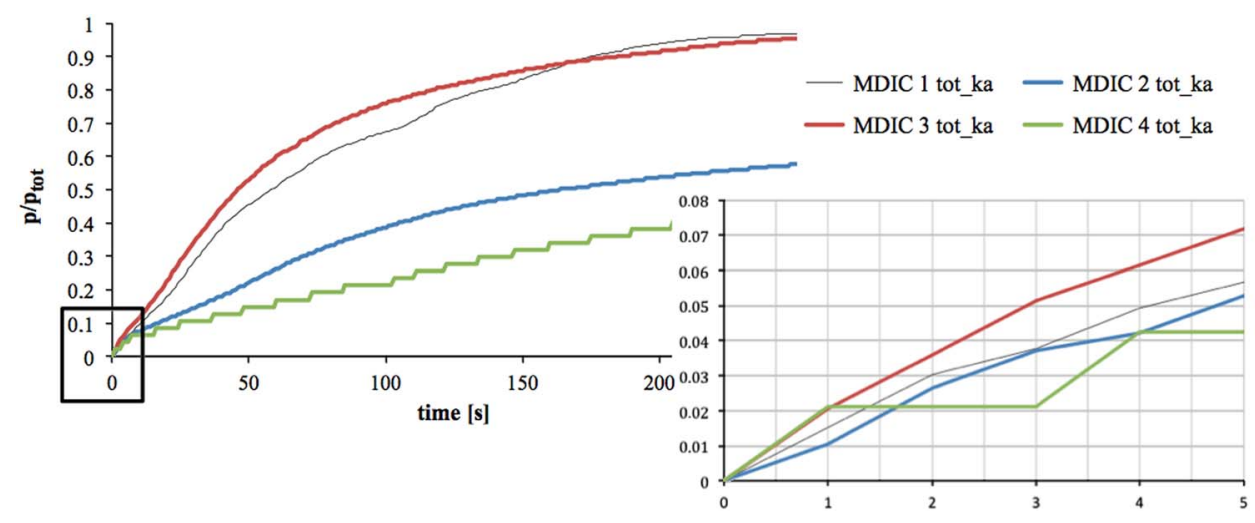

Figure 2 The exemplary course of carbonates decomposition in orthophosphoric acid, in function of time; MDIC 1-the wall's bedding mortar from the church of Nagu (Finland); MDIC 2-lime conglomerate from Cova S'Estora (Mallorca, Spain); MDIC 3-the medieval mortar mixer from Basel Cathedral Hill (Switzerland); MDIC 4-the Roman cocciopesto mortar from Tongeren (Belgium); tot_ka-fragment of bulk mortar without any additional preparation; the ordinate p/ptot represents the proportion of pressure of $\mathrm{CO}_{2}$ collected after time $t$ to the pressure of the whole collected $\mathrm{CO}_{2}$. The more irregular decomposition takes place in Roman cocciopesto mortars, which is connected with finely grained ceramic dust, clay minerals mixed in the binder structure.

Following these preparatory steps, after dissolution with $\mathrm{H}_{3} \mathrm{PO}_{4}$ of selected fractions, the time intervals for collecting gas samples were chosen (first $1,2 \mathrm{~s}, 2-5 \mathrm{~s}, 5-10 \mathrm{~s}, 14 \mathrm{~s}, 25 \mathrm{~s}$ ). The collected $\mathrm{CO}_{2}$ was then graphitized for AMS analysis. The age of the mortar was based on the age of the fraction collected in the shortest time (first 1, $2 \mathrm{~s}$ in case of Sample 1-Finnish mortar and Sample 2-Mallorca burial lime). The longer time intervals of gas collecting (e.g. $14 \mathrm{~s}$ ) provided an additional indicator of carbonate content from another source than the binder (Goslar et al. 2009; Ringbom et al. 2014).

\section{Preparation of Mortar at RICH Laboratory (Brussels, Belgium)}

The method applied at RICH laboratory is described in detail by Van Strydonck et al. 2009. Samples were dry sieved to the fractions: $<38 \mu \mathrm{m}, 38-75 \mu \mathrm{m}$, or $75-125 \mu \mathrm{m}$. The $\mathrm{HCl}$ titration was applied to obtain the $\mathrm{CO}_{2}$. The 38-75 $\mu \mathrm{m}$ fractions were used for the preparation. The total $\mathrm{CO}_{2}$-yield of the sample was determined by complete acid hydrolysis. Based on the total yield, the $\mathrm{CO}_{2}$-release was divided into a number of fractions. The corresponding amounts of hydrochloric acid were applied by titration according to the desired subdivision in fractions. Numerous fractions, if possible 7 , were analyzed. The final age of mortar are reported as the extrapolated age of the fraction 0 .

\section{Preparation of Mortar at Milano-Bicocca Laboratory (Italy)}

Physical procedures applied to separate appropriate material involved: crushing, extraction of lumps and wet sieving to select grains $<500 \mu \mathrm{m}$. The chemical extraction was done by

- Acid digestion $\left(\mathrm{H}_{3} \mathrm{PO}_{4} 85 \%\right)$ of $50-100 \mathrm{mg}$ of the grain fraction with a granulometry below $500 \mu \mathrm{m}$ (selected by wet sieving);

- Acid digestion $\left(\mathrm{H}_{3} \mathrm{PO}_{4} 85 \%\right)$ of $30-40 \mathrm{mg}$ of the lumps with a granulometry above $500 \mu \mathrm{m}$ (selected from all the collected lumps by dry sieving). 
In both cases, $\mathrm{CO}_{2}$ produced during the first $15 \mathrm{~s}$ of the reaction is collected and graphitized and transferred for AMS analyses at CIRCE AMS facility (Caserta, Italy).

For OSL dating, the outer part of the samples was removed in order to eliminate the grains that were exposed to daylight. The quartz fraction was selected under dim red light. All these samples have been crushed and sieved to select grains $<500 \mu \mathrm{m}$. Some physical and chemical treatments were performed following these steps:

- $\mathrm{HCl} 37 \%$ since reaction stopped

- $\mathrm{H}_{2} \mathrm{O}_{2} 36 \%$ vol

- $\quad$ Sieving $125-250 \mu \mathrm{m}$

- Mineral separation with sodium polytungstate solution at $2.67 \mathrm{~g} / \mathrm{cm}^{3}$

- $\mathrm{HF} 40 \%$ for $40 \mathrm{~min}$

- $\mathrm{HCl} 20 \%$ for $15 \mathrm{~min}$

Because no detectable luminescence signal from single grains of quartz was observed, a multigrain aliquot were analyzed. The samples were fixed with silicon oil on stainless-steel discs.

The measurements were performed following the single-aliquot regeneration (SAR) dating protocol (Murray and Wintle 2000) using an automated luminescence system (Risø TL/OSLDA-20) equipped with a ${ }^{90} \mathrm{Sr} /{ }^{90} \mathrm{Y}$ beta source delivering $0.108 \mathrm{~Gy} / \mathrm{s}( \pm 3 \%)$ to the sample position. Quartz OSL was stimulated by an array of blue LEDs (470 $\pm 30 \mathrm{~nm})$ and OSL shine-down curves were detected using a photon counting technique with an EMI 9635QB photomultiplier tube coupled to a 7.5-mm Hoya U-340 filter. The samples were checked for the absence of feldspar contamination using IR stimulation $(830 \pm 10 \mathrm{~nm})$ on irradiated samples. OSL measurements $(40 \mathrm{~s})$ were made at $125^{\circ} \mathrm{C}$, after preheating aliquots for $10 \mathrm{~s}$ at $260^{\circ} \mathrm{C}$. A cut-heat of $160^{\circ} \mathrm{C}$ was applied to each aliquot before the test dose measurement.

In order to calculate the annual dose rate, the Th and $\mathrm{U}$ concentrations of the mortars were measured with total alpha counting using $\mathrm{ZnS}$ scintillator discs (Aitken 1985). ${ }^{40} \mathrm{~K}$ content was deduced from the total concentration of K, obtained by flame photometry. Attenuation of the beta dose was taken into account (Bell 1979). The cosmic ray contribution to the final dose rate was based on Prescott and Hutton (1994). Finally, for each sample the saturated water content was derived from the total porosity of the sample and a reconstructed value of the mean water content was calculated for each mortar sample.

\section{Preparation of Mortar for OSL Analysis IRAMAT-CRP2A Bordeaux}

The preparation of mortar for luminescence dating involved crushing and sieving of inner parts of the samples under dim red light. The size fraction $200-250 \mu \mathrm{m}$ underwent the following chemical treatments:

- $\quad \mathrm{HCl} 37 \%$ (dissolution of carbonates)

- $\mathrm{H}_{2} \mathrm{O}_{2} 15 \%$ (if present, dissolution of organic residues)

- mixture of $\mathrm{H}_{2} \mathrm{SiF}_{6}$ with $\mathrm{HNO}_{3}$ in ratio 9:1 (dissolution of feldspars)

Extracted quartz grains of size fraction 200-250 $\mu \mathrm{m}$ were fixed on stainless steel discs. The total dissolution of feldspar in the etched fractions from mortars was verified before starting the 
dating procedure by IRSL test. All OSL measurements were performed using a TL/OSL DA20 Risø reader using the single aliquot regeneration (SAR) protocol (Murray and Wintle 2000) applying preheat and cut-heat temperatures of $190^{\circ} \mathrm{C}$ and $160^{\circ} \mathrm{C}$, respectively, regeneration doses of $1.4 ; 2.8 ; 5.6 ; 11,2 ; 0 ; 1.4 \mathrm{~Gy}$ and a test dose $2.8 \mathrm{~Gy}$.

Since the single grain OSL measurements did not give any detectable signal, a standard multigrain technique was applied and several tens of grains are analyzed together. In this case, all the grains contribute to the final OSL signal, which results in a measurable OSL response for weakly luminescent mortars, however, some averaging effect due to the presence of well-bleached and poorly bleached grains on the same disc can occur.

The contribution to the annual dose rate arising from mortar matrix (alpha and beta emissions) was evaluated by low background gamma spectrometry (Guibert and Schwoerer 1991; Urbanová et al. 2015). The gamma and cosmic contributions to the annual dose rate could not have been measured in situ (excavations were completed long time ago) and they were therefore assessed using the contents of radioelements $\mathrm{K}, \mathrm{U}$, and Th determined by low background gamma spectrometry, adding the value of $0.23 \pm 0.03 \mathrm{mGy} / \mathrm{yr}$ for cosmic contribution.

According to petrographic, cathodoluminescence, and SEM-EDX observations, the sample did not contain coarse potassium feldspars. This indicates that the annual dose rate is not affected by significant microdosimetric variations, which could complicate the dating process (Guérin et al. 2015; Martin et al. 2015; Urbanová et al. 2015).

\section{RESULTS AND DISCUSSION}

Results of all the analyses performed on the mortar that was distributed as a part of MODIS are summarized in Table 1. All the data are reported in the supplementary Table S1 and discussed by Hayen et al. (2017 this volume).

Table 1 Summary of results obtained for MODIS samples. Independent age control is given as ${ }^{14} \mathrm{C}$ ages of material found in mortar samples. Minimum and maximum ages give the ranges of all ${ }^{14} \mathrm{C}$ ages measured in this intercomparison. OSL ages are recalculated to ${ }^{14} \mathrm{C}$ ages.

\begin{tabular}{lllllll}
\hline $\begin{array}{l}\text { MODIS } \\
\mathrm{nr}\end{array}$ & Description & $\begin{array}{l}\text { Independent } \\
{ }^{14} \mathrm{C} \text { age BP }\end{array}$ & $\begin{array}{l}\text { MODIS } \\
\text { MinAge }\end{array}$ & $\begin{array}{l}\text { MODIS } \\
\text { MaxAge }\end{array}$ & $\begin{array}{l}\text { Mean value/ } \\
\text { criteria }\end{array}$ & $\chi^{2}$-test \\
\hline 1 & Finnish mortar & $\begin{array}{l}515 \pm 9 \\
\text { (wood) }\end{array}$ & $159 \pm 75$ & $1040 \pm 70$ & $\begin{array}{l}505 \pm 8 \\
(<550 \mathrm{BP})\end{array}$ & $\begin{array}{l}\mathrm{df}=16 \\
\mathrm{~T}=20.6 \\
(5 \% 26.3)\end{array}$ \\
2 & $\begin{array}{l}\text { Mallorca lime } \\
\text { burial }\end{array}$ & $\begin{array}{l}2336 \pm 30 \\
\text { (charcoal) }\end{array}$ & $2345 \pm 144$ & $4110 \pm 32$ & $\begin{array}{l}2376 \pm 22 \\
(<2500 \mathrm{BP})\end{array}$ & $\begin{array}{l}\mathrm{T}=0.1 \\
\mathrm{df}=3\end{array}$ \\
3 & Basel mortar & $\begin{array}{l}1324 \pm 18^{*} \\
(\text { charcoal) }\end{array}$ & $1491 \pm 50$ & $8240 \pm 51$ & - & - \\
4 & $\begin{array}{l}1739 \pm 30 \\
\text { Roman } \\
\text { cocciopesto }\end{array}$ & $712 \pm 25$ & $2650 \pm 150$ & - & - \\
\hline
\end{tabular}

*Mean value of two samples (ETHZ_charcoal: $1313 \pm 22$ BP and POZN_charcoal: $1345 \pm 30 \mathrm{BP}$ ) results in ${ }^{14} \mathrm{C}$ age of $1324 \pm 18$ BP $\left(\chi^{2}\right.$-test: $\left.\mathrm{df}=1 \mathrm{~T}=0.7[5 \% 3.8]\right)$. 


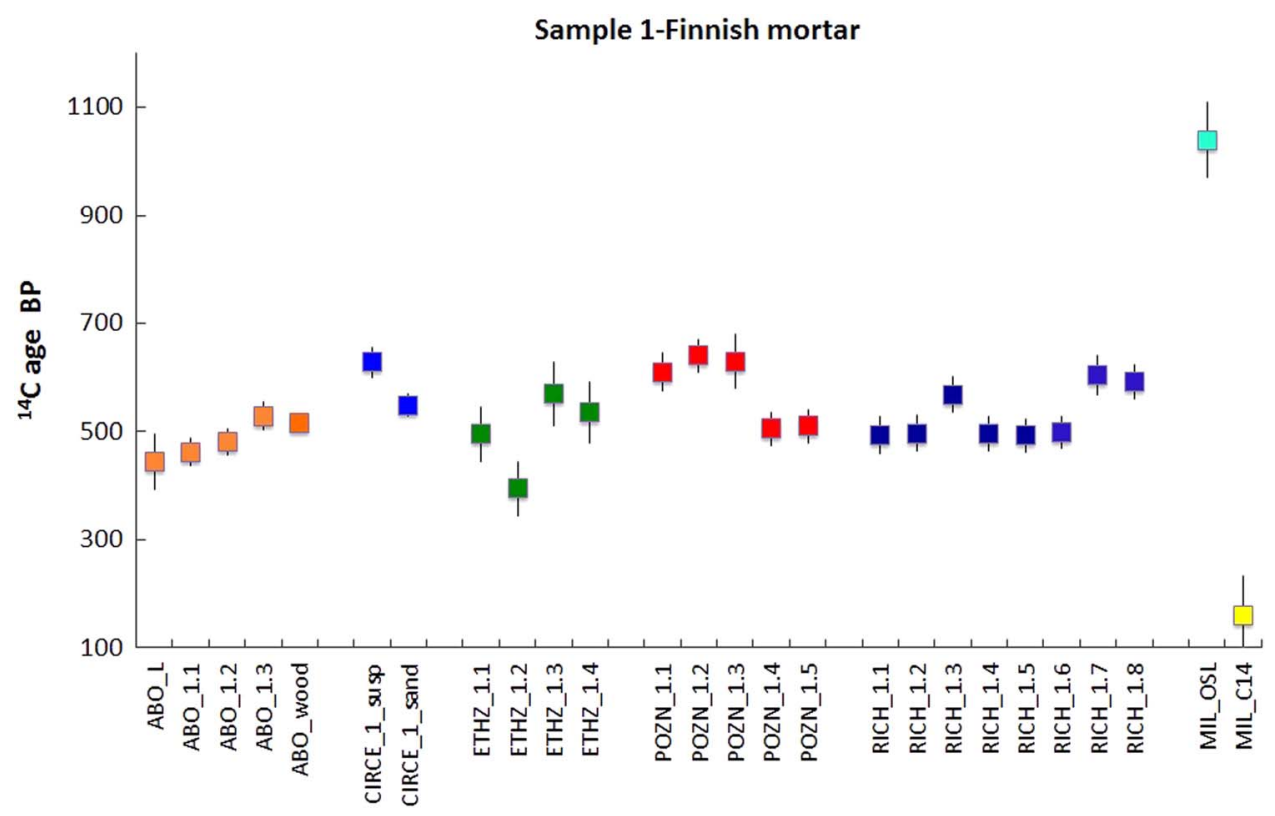

Figure 3 Sample of Finish mortar - the independent age was obtained on wood ABO_wood $512 \pm 9$ BP. Additional notes: L-lump, fractions of different dissolution steps (supplementary Table S1) are shown as LAB_1.2, LAB_1.3, etc. Results of each laboratory are shown in different colors (ordered as in Table 1; refer to online version for colors).

\section{Discussion: Sample 1-Finnish Mortar}

Results obtained by all the laboratories for the medieval Finnish church (Sample 1) are summarized in Figure 3. With an exception of the Poznań laboratory, which received original fragments of mortar, others obtained pre-sieved fraction $45-72 \mu \mathrm{m}$ of this sample. The ${ }^{14} \mathrm{C}$ ages appear consistent for most of the laboratories and close to the independent measurement on wood, which should give a maximum age for the building. If samples older than $600 \mathrm{BP}$ (fractions that contain old component) and the one too young sample of MIL_C14 are not included in the combined ${ }^{14} \mathrm{C}$ age, the resulting age of $505 \pm 8 \mathrm{BP}\left(\chi^{2}\right.$-test: $\mathrm{df}=16 \mathrm{~T}=20.6$ $\left[5 \%\right.$ 26.3]) is comparable to the ${ }^{14} \mathrm{C}$ age of wood $515 \pm 9 \mathrm{BP}$, calibrated 1410-1432 AD (95.4\% conf. level).

\section{Discussion: Sample 2-Mallorca Burial Lime}

Figure 4 shows results of dating Mallorca burial lime. Two samples were distributed: fine fraction $<500 \mu \mathrm{m}$ and original lime $(\mathrm{F})$. The age of the burial is considered to be close to the measurement on charcoal and bone $(\mathrm{RICH}$ _charcoal and RICH_bone: $2336 \pm 30$ and $2442 \pm 30 \mathrm{BP}$, respectively). ${ }^{14} \mathrm{C}$ ages of the fast dissolving component obtained on fraction with grain size smaller than $100 \mu \mathrm{m}\left(\mathrm{ABO} \_2.1: 46-75 \mu \mathrm{m}\right.$; $2 \mathrm{~s}$; ETHZ_2a.1\&2: 45-63 $\mu \mathrm{m}$; 1-3 and 4-6 s, POZN_2: 80-100 $\mu \mathrm{m} ; 2 \mathrm{~s}$ ) yields youngest ages (see Figure 4). The combined radiocarbon age of these samples is $2377 \pm 22 \mathrm{BP}\left(\chi^{2}\right.$-test: $\left.\mathrm{df}=3 \mathrm{~T}=0.1[5 \% 7.8]\right)$, calibrated $515-396 \mathrm{BC}$ (95.4\% conf. level), which is very close to the age of the charcoal (2366 $\pm 30 \mathrm{BP})$ obtained by RICH laboratory. The bone is only slightly older ( $2442 \pm 30 \mathrm{BP})$ excluding older ages of mortar which were obtained on fraction with grain size $<500 \mu \mathrm{m}$. At ETH laboratory too old ages were obtained for first and second fast dissolution product for the whole $<500 \mu \mathrm{m}$ fraction (Figure 4). Similar results, which gave ages that were older than expected, were obtained by other 


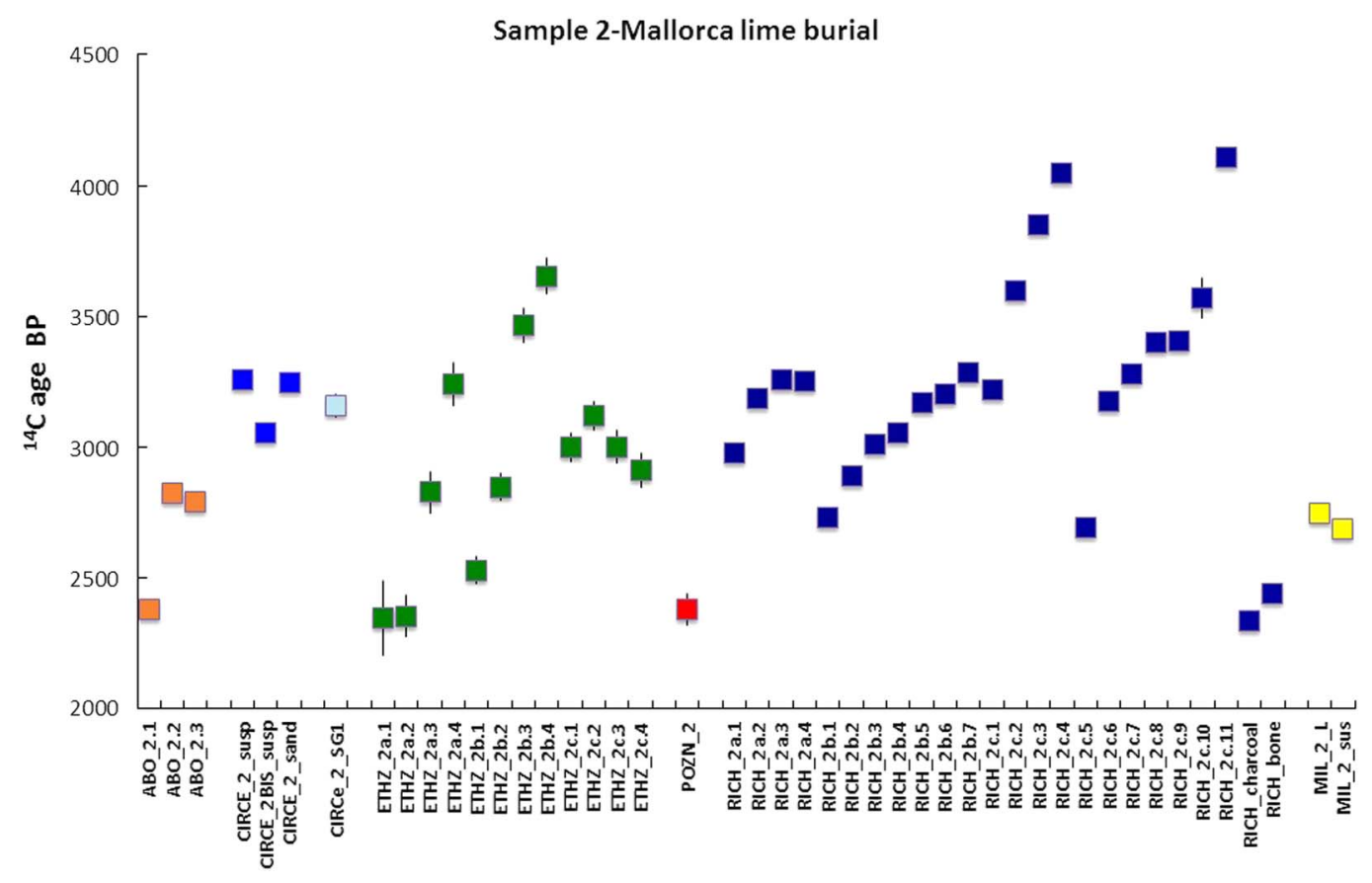

Figure 4 Sample 2_Mallorca lime burial. Additional notes: Fractions of different dissolution steps (see supplementary Table $\mathrm{S} 1$ ) are shown as LAB_2.1, LAB_2.2 etc. ETHZ: 3 sets of analyses: a, b, c. RICH: 3 sets of analyses: a (HCl-4), b (HCl-7), c (HCl-4). Results of each laboratory are shown in different colors (ordered as in Table 1; refer to online version for colors).

laboratories. These results show that the only effective separation involved both methods: fine grain size and fast dissolution.

\section{Discussion: Sample 3-Basel Mortar}

Figure 5 shows that independently of the dating method (OSL or ${ }^{14} \mathrm{C}$ ), the preparation method or grain-size, all analyses resulted in ages older than the charcoal found in mortar. The combined age of two charcoal samples (ETHZ_charcoal: 1313 \pm 22 BP and POZN_charcoal: $1345 \pm 30 \mathrm{BP})$ results in ${ }^{14} \mathrm{C}$ age of $1324 \pm 18 \mathrm{BP}\left(\chi^{2}\right.$-test: $\mathrm{df}=1 \mathrm{~T}=0.7$ [5\% 3.8]) (Table 1), calibrated 655-764 AD (95.4\% conf. level). The difference between mortar and charcoal is even larger when two ${ }^{14} \mathrm{C}$ ages: $1055 \pm 45 \mathrm{BP}$ and $1105 \pm 40 \mathrm{BP}$, which were obtained on charcoal prior to the MODIS (Hayen et al. 2017 this volume), are considered. The picture is even more complicated by the age of a bone: $1625 \pm 55$ BP (Hayen et al. 2017 this volume). This scatter of ${ }^{14} \mathrm{C}$ ages suggests that this sample of mortar is highly heterogeneous. The presence of an old component (Table 1; sample RICH_3a.5: $8240 \pm 51$ BP) might well explain too old radiocarbon age (Roman instead of Medieval), however it does not explain the scatter of ages observed for charcoal and bone. This complicated picture points to a mixed source of sample material.

\section{Discussion: Sample 4-Roman Cocciopesto}

As can be seen from Figure 6, results obtained by all the laboratories are consistently younger than the expected Roman age (1739 \pm 32 BP; RICH_charcoal). With an exception of the two oldest fraction (POZN_4.3: $2650 \pm 150$ BP and RICH_4.7: $1540 \pm 34$ BP) most of the results range from 700 to $1300 \mathrm{BP}$. Although difficulty in dating cocciopesto has been known from 


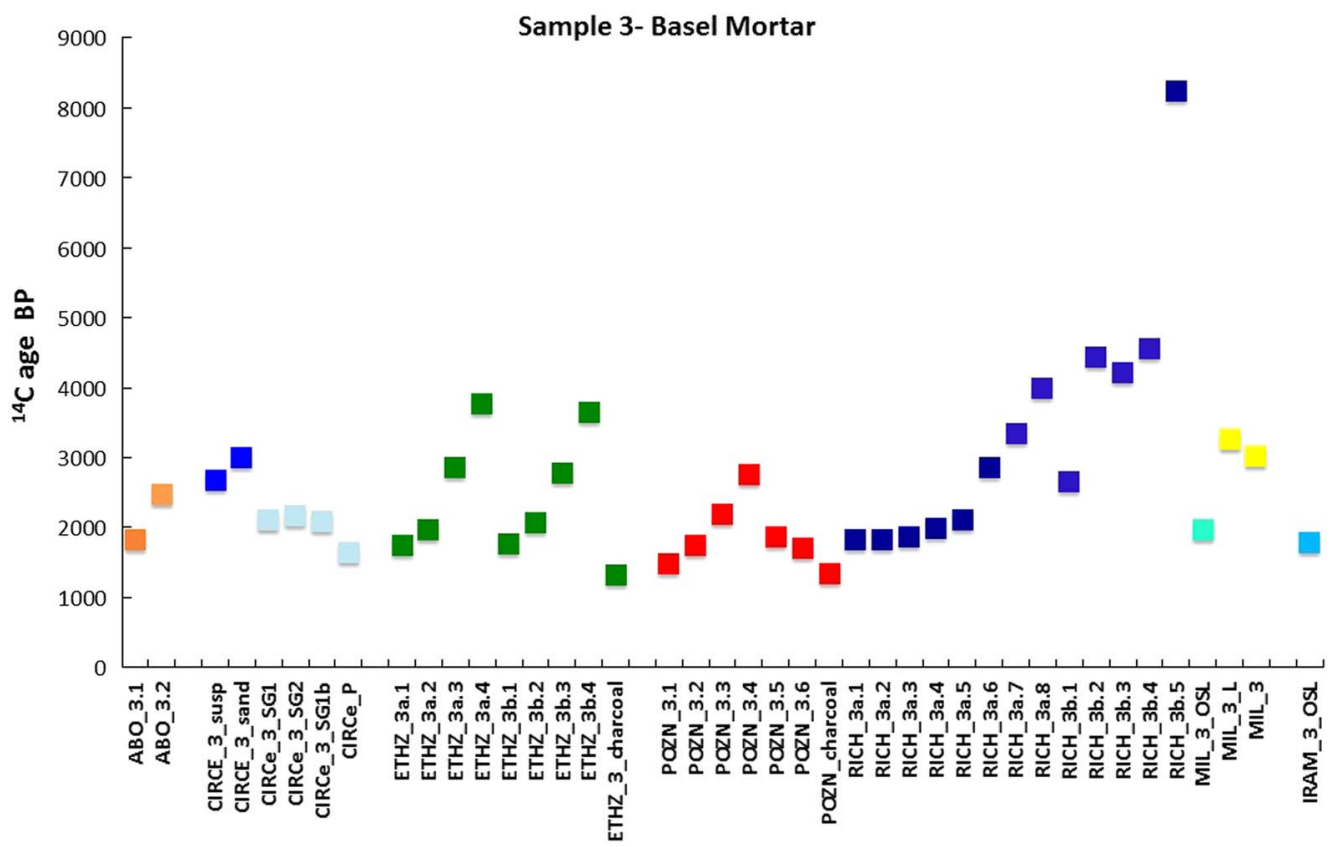

Figure 5 Sample 3 Basel mortar: This sample was previously dated as discussed by Hayen et al. (2016, 2017). ${ }^{14} \mathrm{C}$ age of charcoal found in the mortar of MODIS is $1313 \pm 22 \mathrm{BP}$ (ETHZ_charcoal).

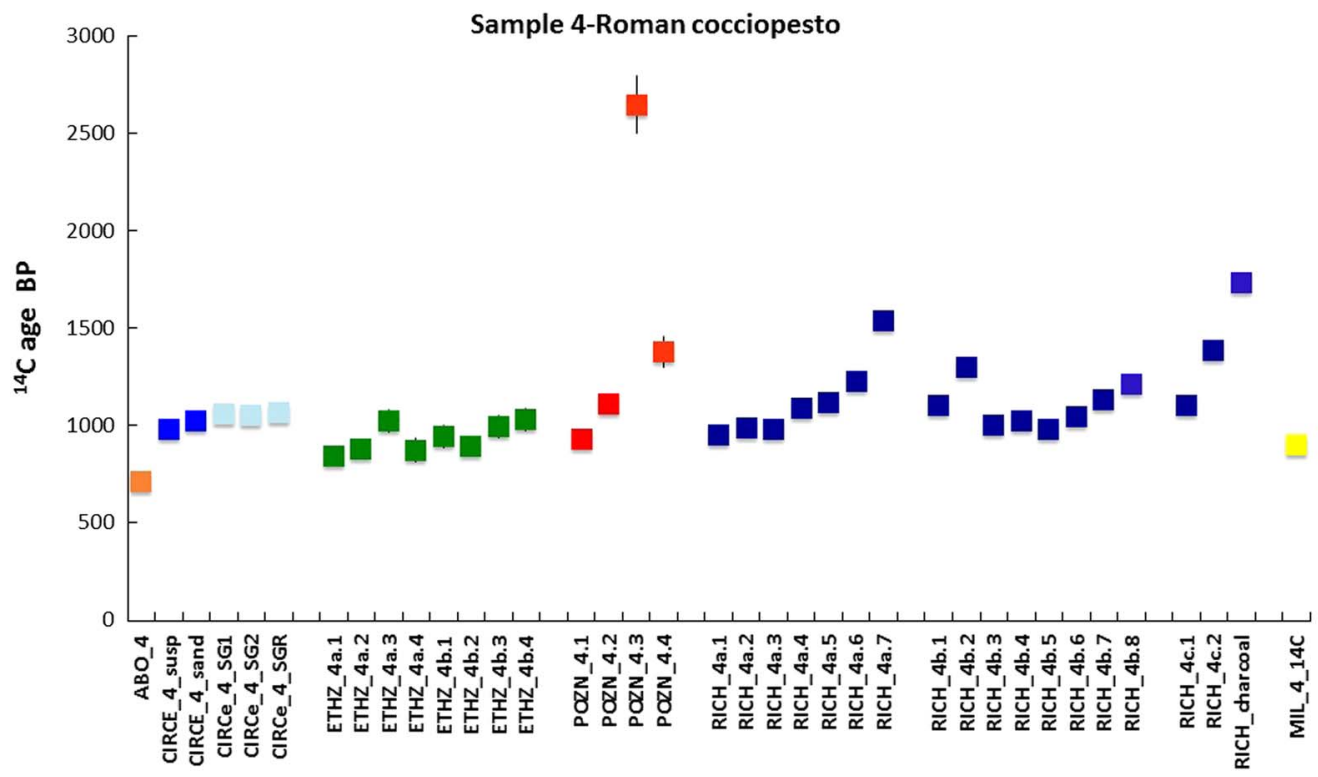

Figure 6 Sample 4 Roman coccipesto: Charcoal from this mortar was previously dated at RICH laboratory (Hayen et al. 2016, 2017). ${ }^{14} \mathrm{C}$ age of charcoal was $1739 \pm 32 \mathrm{BP}\left(\mathrm{RICH} \_\right.$charcoal).

previous studies (Hodgins et al. 2011; Ringbom et al. 2011, 2014; Michalska et al. this volume) consistently too young ages, as compared to the expected one, can probably be explained by processes such as the delayed hardening of mortar that was sampled from deep inside the wall 
(Hayen et al. 2017). In this case, nearly coherent ages of the first fractions (Figure 6) obtained by the laboratories date the time of hardening, probably delayed by the impermeability of coccipesto as well as the sample depth (Heinemeier et al. 1997, 2010).

\section{SUMMARY}

Two OSL laboratories and seven ${ }^{14} \mathrm{C}$ laboratories performed analysis on mortar of MODIS study by applying various procedures.

The following common points for ${ }^{14} \mathrm{C}$ preparation protocols are based on the MODIS comparison study:

- $\quad$ Prescreening of samples

- Particle size (by sieving or suspended fractions centrifuge/gravity)

- Dissolution (\% of the total or the time of dissolution)

- $\quad$ All ${ }^{14} \mathrm{C}$ laboratories apply more than one ${ }^{14} \mathrm{C}$ analysis per sample

Both OSL laboratories based the dating process on the analyses of coarse quartz fractions measured by the multigrain technique. The OSL dating results obtained by multigrain technique from the Basel mortar, which contained enough quartz fraction for OSL analysis, showed general agreement both between OSL laboratories and with ${ }^{14} \mathrm{C}$ dating results.

Overall, the results of this first intercomparison provide important observations for a choice of material and prospects for a successful mortar dating. The two homogeneous samples: Sample_1 (Finnish Mortar) and Sample_2 (Mallorca Burial Lime) were successfully dated. However, the complicated material such as Sample 3 (Basel Mortar) and Sample 4 (Roman Cocciopesto) gave coherent results but different from expected ages. These results highlight the complexity of ${ }^{14} \mathrm{C}$ dating of mortars indicating the potential but also its limits. Moreover, the exchange of knowledge between laboratories and observations made during this study are an important factor for understanding the results of dating mortars.

\section{ACKNOWLEDGMENTS}

We thank Sophie Hueglin for providing the Basel Mortar sample as well as many discussions of the archeological aspects of the sample. IH thanks LIP ETHZ laboratory for the support: Mantana Maurer and Maria Belen Röttig for laboratory preparation, Laura Hendriks and Lukas Wacker for measurements using GIS AMS.

\section{SUPPLEMENTARY MATERIALS}

To view supplementary material for this article, please visit https://doi.org/10.1017/RDC. 2017.112

\section{REFERENCES}

Addis A, Secco M, Preto N, Marzaioli F, Passariello I, Brogiolo GP, Chavarria Arnau A, Artioli G, Terrasi F. 2016. New strategies for radiocarbon dating of mortars: Multi-step purification of the lime binder. Proceedings of 4th Historic Mortars, Santorini, Greece 10-12 October 2016.

Aitken MJ. 1985. Thermoluminescence Dating. London: Academic Press. 267 p.
Bell WT. 1979. Attenuation factors to absorbed dose in quartz inclusions for thermoluminescence dating. Ancient TL 8:2-13.

Binda I, Baronio G. 1988. Survey of brick-binder adhesion in 'powdered brick' mortars and plasters, Masonry International Journal 2: pp. 87-92.

Fahrni SM, Gaggeler HW, Hajdas I, Ruff M, Szidat S, Wacker L. 2010. Direct measurements of small 
C-14 samples after oxidation in quartz tubes. Nuclear Instruments and Methods in Physics Research B 268:787-9.

Folk RL, Valastro S. 1976. Successful technique for dating of lime mortar by carbon-14 J. Field Archaeology 3(2)203-8.

Folk RL, Valastro S. 1979. Dating of lime mortar by ${ }^{14} \mathrm{C}$. In: Berger R, Suess H, editors. Radiocarbon Dating: Proceedings of the Ninth International Conference. Berkeley: University of California Press. p 721-30.

Goslar T, Nawrocka D, Czernik J. 2009. Foraminiferous limestones in ${ }^{14} \mathrm{C}$ dating of mortar. Radiocarbon 51(2):857-66.

Goedicke C. 2011. Dating mortar by optically stimulated luminescence: a feasibility study. Geochronometria 38(1):42-9.

Goedicke C. 2003. Dating historical calcite mortar by blue OSL: results from known age samples. Radiation Measurements 37:409-15.

Guérin G, Myank J, Thomsen K, Murray A, Mercier N. 2015. Modelling dose rate to single grains of quartz in well-sorted sand samples: the dispersion arising from the presence of potassium feldspars and implications for single grain OSL dating. Quaternary Geochronology 27:52-65.

Guibert P, Schvoerer M. 1991. TL-dating: Low background gamma spectrometry as a tool for the determination of the annual dose. Nuclear Tracks and Radiation Measurements 14:155-61.

Hajdas I, Trumm J, Bonani G, Biechele C, Maurer M, Wacker L. 2012. Roman ruins as an experiment for radiocarbon dating of mortar. Radiocarbon 54(3-4):897-903.

Hayen R, Van Strydonck M, Boaretto E, Lindroos A, Heinemeier J, Ringbom Å, Hueglin S, Michalska D, Hajdas I, Marzaoili F, Maspero F, Galli A, Artioli G, Moreau Ch, Guibert P, Caroselli M. 2016. Absolute dating of mortars - integrating chemical and physical techniques to characterize and select the mortar samples. Proceedings of the 4th Historic Mortars Conference - HMC2016. 656-67.

Hayen R, Van Strydonck M, Fontaine L, Boudin M, Lindroos A, Heinemeier J, Ringbom A, Michalska D, Hajdas I, Hueglin S, Marzaioli F, Terrasi F, Passariello I, Capano M, Maspero F, Panzeri L, Galli A, Artioli G, Addis A, Secco M, Boaretto E, Moreau C, Guibert P, Urbanova P, Czernik J, Goslar T, Caroselli M. 2017. Mortar dating methodology: intercomparison of available methods. Radiocarbon 59(6):this volume.

Heinemeier J, Jungner H, Lindroos A, Ringbom A, von Konow T, Rud N. 1997. AMS ${ }^{14} \mathrm{C}$ dating of lime mortar. Nuclear Instruments and Methods in Physics Research B 123:487-95.

Heinemeier J, Ringbom $\AA$, Lindroos A, Sveinbjörnsdóttir ÁE. 2010. Successful AMS ${ }^{14} \mathrm{C}$ dating of non-hydraulic lime mortars from the medieval churches of the Åland Islands, Finland. Radiocarbon 52(1):171-204.
Hodgins G, Lindroos A, Ringbom Å, Heinemeier J, Brock F. 2011. ${ }^{14} \mathrm{C}$ dating of roman Mortars preliminary tests using diluted hydrochloric acid injected in batches. Commentationes Humanarum Litterarum 128:209-13.

Labeyrie J, Delibrias G. 1964. Dating of old mortars by the carbon-14 method. Nature 201(4920):742.

Lichtenberger A, Lindroos A, Raja R, Heinemeier J. 2015. Radiocarbon analysis of mortar from Roman and Byzantine water management installations in the Northwest Quarter of Jerash, Jordan. Journal of Archaeological Science: Reports 2:114-27.

Lindroos A, Heinemeier J, Ringbom Å, Braskén M, Sveinbjörnsdóttir Á. 2007. Mortar dating using AMS ${ }^{14} \mathrm{C}$ and sequential dissolution: examples from medieval, non-hydraulic lime mortars from the Åland Islands, SW Finland. Radiocarbon 49(1):47-67.

Lindroos A, Heinemeier J, Ringbom Å, Brock F, Sonck-Koota P, Pehkonen M, Suksi J. 2011. Problems in radiocarbon dating of Roman Pozzolana mortars. In: Ringbom $\AA$, Hohlfelder R, editors. Building Roma Aeterna. Current research on Roman Mortar and Concrete. Proceedings of the conference March 27-29, 2008. Commentationes Humanarum Litterarum 128: 214-30.

Martin L, Mercier N, Incerti S, Lefrais Y, Pecheyran C, Guérin G, Jarry M, Bruxelles L, Bon F, Pallier C. 2015. Dosimetric study of sediments at the beta dose rate scale: characterization and modelization with the DosiVox software. Radiation Measurements 81:134 41. DOI: 10.1016/j.radmeas.2015.02.008.8.

Marzaioli F, Lubritto C, Nonni S, Passariello I, Capano M, Terrasi F. 2011. Mortar radiocarbon dating: Preliminary accuracy evaluation of a novel methodology. Analytical Chemistry 83(6):2038-45.

Marzaioli F, Nonni S, Passariello I, Capano M, Ricci P, Lubritto C, De Cesare N, Eramo G, Castillo JAQ, Terrasi F. 2013. Accelerator mass spectrometry ${ }^{14} \mathrm{C}$ dating of lime mortars: methodological aspects and field study applications at CIRCE (Italy). Nuclear Instruments and Methods in Physics Research B 294:246-51.

Marzaioli F, Borriello G, Passariello I, Lubritto C, De Cesare N, D’Onofrio A, Terrasi F. 2008. Zinc reduction as an alternative method for AMS radiocarbon dating: Process optimization at CIRCE. Radiocarbon 50(1):139-49.

McCrea JMJ. 1950. Isotopic chemistry of carbonates and a paleo-temperature scale. J. Chem. Phys. 18:849-57.

Michalska D, Czernik J, Gosar T. 2017. Methodological aspect of mortars dating (Poznań, Poland, MODIS). Radiocarbon 59(6):submitted.

Michalska D, Czernik J. 2015. Carbonates in leaching reactions in context of ${ }^{14} \mathrm{C}$ dating. Nuclear Instruments and Methods in Physics Research B 361:431-9.

Michalska D, Pazdur A, Czernik J, Szczepaniak M, Żurakowska M. 2013. Cretaceous aggregate and 
reservoir effect in dating of binding materials. Geochronometria 40(1):33-41.

Murray AS, Wintle A. 2000. Luminescence dating of quartz using an improved single-aliquot regenerative dose protocol. Radiation Measurements 32:523-38.

Nawrocka-Michalska D, Michczyńska DJ, Pazdur A, Czernik J. 2007. Radiocarbon chronology of the ancient settlement on the Golan Heights. Radiocarbon 49(2):625-37.

Nawrocka D, Czernik J, Goslar T. 2009. ${ }^{14} \mathrm{C}$ dating of carbonate mortars from Polish and Israeli sites. Radiocarbon 51(2):857-66.

Nawrocka D, Michniewicz J, Pawlyta J, Pazdur A. 2005. Application of radiocarbon method for dating of lime mortars. Geochronometria 24: 109-15.

Nonni S, Marzaioli F, Secco M, Passariello I, Capano M, Lubritto C, Mignardi S, Tonghini C, Terrasi F. 2013. ${ }^{14} \mathrm{C}$ mortar dating: the case of the Medieval Shayzar Citadel, Syria. Radiocarbon 55(2):514-25.

Panzeri L. 2013. Mortar and surface dating with optically stimulated luminescence (OSL): innovative techniques for the age determination of buildings. Nuovo Cimento della 36(4):205-16.

Prescott JR, Hutton JT. 1994. Cosmic ray contribution to dose rates for luminescence and ESR dating. Radiation Measurements 23(2-3): 497-500.

Ringbom Å, Remmer C. 1995. Ålands kyrkor, Volym I, Hammarland och Eckerö, Naturvetenskaplig datering. Mariehamn. p 60-8.

Ringbom A, Heinemeier J, Lindroos A, Brock F. 2011. Mortar dating and roman pozzolana, results and interpretations. In: Ringbom $\AA$, Hohlfelder $\mathrm{R}$, editors. Building Roma Aeterna. Current research on Roman Mortar and Concrete. Proceedings of the conference March 27-29, 2008. Commentationes Humanarum Litterarum 128:187-208.

Ringbom $\AA$, Lindroos A, Heinemeier J, Sonck-Koota P. 2014. 19 years of mortar dating: learning from experience. Radiocarbon 56(2):619-35.

Stuiver M, Smith CS. 1965. 6th International Conference on Radiocarbon and Tritium Dating, Pullman, WA. p 338-343.

Van Strydonck M, Dupas M, Dauchot-Dehon M, Pachiaudi C, Marechal J. 1983a. A further step in the radiocarbon dating of old mortars: Bull Kon Inst Kunstpatrimonium, v XIX, 1982/83. p 155-71.
Van Strydonck M, Dupas M, Dauchot-Dehon M. 1983b. Radiocarbon dating of old mortars. In: Mook WG, Waterbolk HT, editors. 14C and Archaeology, Proceedings. PA C T 8:337-43.

Van Strydonck M, Dupas M, Dauchot-Dehon M, Pachiaudi Ch, Marechal J. 1986. The influence of contaminating carbonate and the variations of $\delta^{13} \mathrm{C}$ in mortar dating. Radiocarbon 28(2A):702-10.

Van Strydonck M Boudin, De Mulder G. 2009. ${ }^{14} \mathrm{C}$ dating of cremated bones: the issue of sample contamination. Radiocarbon 51(2):553-68.

Van Strydonck M, Aramburu J, Fernández Martínez A, Alvarez Jurado-Figueroa M, Boudin M, De Mulder G. 2017. Radiocarbon dating of the Son Pellisser lime burial (Calvià, Mallorca). Journal of Archaeological Science: Reports 11:471-9.

Terrasi F, De Cesare N, D’Onofrio A, Lubritto C, Marzaioli F, Passariello I, Rogalla D, Sabbarese C, Borriello G, Casa G, Passariello I. 2008. High precision ${ }^{14} \mathrm{C}$ AMS at CIRCE. Nuclear Instruments and Methods in Physics Research B 266:2221-4.

Urbanová P, Hourcade D, Ney C, Guibert P. 2015. Sources of uncertainties in OSL dating of archaeological mortars: the case study of the Roman amphitheatre Palais-Gallien in Bordeaux. Radiation Measurements 72:100-10.

Urbanová P, Delaval E, Dufresne P, Lanos P, Guibert P. 2016. Multi-method dating of Grimaldi castle foundations in Antibes, France. ArchéoSciences Revue d'archéométrie 40:17-33.

Urbanová P, Guibert P. 2017a. A review on Single grain OSL dating of mortars: a methodological study of five reference archaeological sites. Geochronometria. DOI: 10.1515/geochr-2015-0050.

Urbanová P, Guibert P. 2017b. La mesure du temps par luminescence : datation de réemplois dans la crypte de Saint Seurin à Bordeaux, dossier «Atelier doctoral. Les remplois en architecture entre Antiquité et Moyen Âge » des. Mélanges de l'École française de Rome, 129, 1.

Vogel JS, Southon JR, Nelson DE, Brown TA. 1984. Performance of catalytically condensed carbon for use in accelerator mass spectrometry. Nuclear Instruments and Methods in Physics Research B 5:289.

Zacharias N, Mauz B, Michael CT. 2002. Luminescence quartz dating of lime mortars. A first research approach. Radiation Protection Dosimetry 101:379-82. 